\title{
Plasmodium falciparum uses vitamin E to avoid oxidative stress
}

\author{
Rodrigo A. C. Sussmann, Wesley L. Fotoran, Emilia A. Kimura and Alejandro M. Katzin ${ }^{*}$
}

\begin{abstract}
Background: Plasmodium falciparum is sensitive to oxidative stress in vitro and in vivo, and many drugs such as artemisinin, chloroquine and cercosporin interfere in the parasite's redox system. To minimize the damage caused by reactive radicals, antioxidant enzymes and their substrates found in parasites and in erythrocytes must be functionally active. It was shown that $P$. falciparum synthesizes vitamin $E$ and that usnic acid acts as an inhibitor of its biosynthesis. Vitamin $E$ is a potent antioxidant that protects polyunsaturated fatty acids from lipid peroxidation, and this activity can be measured by detecting its oxidized product and by evaluating reactive oxygen species (ROS) levels.

Results: Here, we demonstrated that ROS levels increased in P. falciparum when vitamin E biosynthesis was inhibited by usnic acid treatment and decreased to basal levels if exogenous vitamin E was added. Furthermore, we used metabolic labelling to demonstrate that vitamin E biosynthesized by the parasite acts as an antioxidant since we could detect its radiolabeled oxidized product. The treatment with chloroquine or cercosporin of the parasites increased the ratio between a-tocopherolquinone and a-tocopherol.
\end{abstract}

Conclusions: Our findings demonstrate that vitamin E produced endogenously by $P$. falciparum is active as an antioxidant, probably protecting the parasite from the radicals generated by drugs.

Keywords: Malaria, Plasmodium falciparum, Oxidative stress, Tocopherol, Usnic acid, Antimalarials

\section{Background}

Malaria remains one of the most important infectious diseases globally. In 2015, 214 million cases of malaria and 438,000 deaths were reported [1]. One of the problems of malaria control is the emergence and spread of $P$. falciparum strains resistant to available antimalarials. Artemisinin derivatives were the only drug that did not present a disseminated resistance, but in 2014, a molecular marker for artemisinin resistance was identified [2]. In view of this problem, several groups have been working to identify new targets for antimalarials.

The apicoplast, an organelle present in most apicomplexans, including Plasmodium spp., is a non-photosynthetic plastid homologous to the chloroplasts of plants and algae that harbors pathways with similarities to those in plants plastids and cyanobacteria, including the 2-Cmethyl-D-erythritol 4-phosphate (MEP) isoprenoid biosynthesis pathway [3, 4]. In 2011, Yeh \& DeRisi [5] demonstrated that the only essential apicoplast function

\footnotetext{
* Correspondence: amkatzin@icb.usp.br

Department of Parasitology, Institute of Biomedical Sciences, University of São Paulo, São Paulo, Brazil
}

(c) The Author(s). 2017 Open Access This article is distributed under the terms of the Creative Commons Attribution 4.0 International License (http://creativecommons.org/licenses/by/4.0/), which permits unrestricted use, distribution, and reproduction in any medium, provided you give appropriate credit to the original author(s) and the source, provide a link to the Creative Commons license, and indicate if changes were made. The Creative Commons Public Domain Dedication waiver (http://creativecommons.org/publicdomain/zero/1.0/) applies to the data made available in this article, unless otherwise stated. is to supply the demand of isopentenyl pyrophosphate (IPP) in P. falciparum. Because the isoprenoids are biosynthesized in humans by the mevalonate pathway, the MEP pathway is an interesting target against which to develop new antimalarials. Our group previously demonstrated that MEP pathway is active in the intraerythrocytic stages of $P$. falciparum [3] and synthesizes dolichol of 11-12 isoprenic units [6], ubiquinone [7], dolichylated/ isoprenylated proteins $[8,9]$, carotenoids [10], vitamin $\mathrm{E}$ ( $\alpha$-tocopherol) [11] and menaquinone [12].

Plasmodium falciparum is sensitive to oxidative stress in vitro and in vivo, and a number of drugs act on the parasite redox system. Examples of these drugs are artemisinin [13], chloroquine [14] and cercosporin [15]. To minimize the damage caused by reactive oxygen (ROS) or nitrogen (RNS) species, enzymes of the antioxidant pathway must be functionally active [16].

Several enzymes of the glutathione system have been described in Plasmodium species. These include glutathione synthase [17] and reductase [18], superoxide dismutase [19], glutamate dehydrogenase [20] and glucose 6phosphate dehydrogenase [21]. Additionally, the parasite 
has a functional thioredoxin system with thioredoxin reductase [22], thioredoxin [23], thioredoxin peroxidase [24] and 1 cys-peroxyredoxin [25] and $\alpha$-tocopherol [11].

Final products of the isoprenoid biosynthesis such $\alpha$ tocopherol may act as antioxidants and in membrane stabilization, as described in plants [26] and cyanobacteria [27]. However, to support the hypothesis that the role of $\alpha$-tocopherol biosynthesized by the parasite is an active antioxidant in the redox systems, it is necessary to detect its oxidized product ( $\alpha$-tocopherolquinone) and evaluate ROS levels.

$\alpha$-Tocopherol was shown to be synthesized by all replicative intraerythrocytic stages via the isoprenoid pathway [11]. This biosynthesis of $\alpha$-tocopherol is inhibited by usnic acid and increases if the parasite is cultivated in a higher oxygen tension [11]. Accordingly, the lipid peroxidation increases in $P$. falciparum culture treated with usnic acid [11]. This is expected since the main function of vitamin $\mathrm{E}$ is to avoid autoxidation of polyunsaturated fatty acids [28, 29].

Given the fact all the previous observations indicated that vitamin $\mathrm{E}$ is involved in redox protection of membranes, we set out to directly prove the presence of oxidized intermediate of this molecule, further underlining its antioxidant role in Plasmodium blood stage metabolism.

\section{Methods}

\section{Plasmodium falciparum culture}

The $P$. falciparum strain 3D7 was cultured in vitro according to Trager \& Jensen [30] with modifications [11]. The cultures (approximately 15\% parasitemia) were initially synchronized in ring stages (6-22 h after the invasion) by treatment with $5 \%(w / v)$ D-sorbitol solution in water. The parasites were maintained in culture until the development of trophozoite (26-34 h after reinvasion) or schizont (38-48 $\mathrm{h}$ after reinvasion) stages and then synchronized by gelatin flotation [31]. Parasite development was monitored by daily microscopic evaluation of Giemsa-stained thin smears.

\section{Fluorescence microscopy}

Uninfected and infected erythrocytes cells with $P$. falciparum were stained with $5 \mu \mathrm{M}$ CellRox for $30 \mathrm{~min}$ in PBS. In the last 5 min of incubation, DAPI nucleic acid stain was added to a final concentration of $200 \mathrm{nM}$. As a positive control, the same procedure was done in parallel with uninfected and infected erythrocytes incubated with $0.5 \mu \mathrm{M} \mathrm{H}_{2} \mathrm{O}_{2}$. The cells were washed $3 \times$ with phosphate-

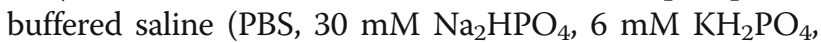
$120 \mathrm{mM} \mathrm{NaCl}, \mathrm{pH} \mathrm{7.4),} \mathrm{mounted} \mathrm{on} \mathrm{glass} \mathrm{slides} \mathrm{and}$ coverslips and fluorescence microscopy images were acquired on a camera (Axio Cam HRc, Zeiss, Göttingen, Germany) connected to an optical microscope (up to 100x) (Axio Imager M2, Zeiss, Göttingen, Germany).
Fluorescent filters used were 02 DAPI $(358 \mathrm{~nm} / 463 \mathrm{~nm})$ and $63 \mathrm{HE}$ MRFP (585 nm/608 nm) (Excitation/Emission, respectively).

\section{ROS levels}

The cell-permeant CellRox deep red (Molecular Probes ${ }^{\oplus}$, Eugene, USA) reagent is sensitive to superoxide anion $\left(\mathrm{O} \cdot{ }_{2}^{-}\right)$and hydroxyl radical $\left({ }^{\circ} \mathrm{OH}\right)$ and was used to measure the ROS levels. Uninfected and infected erythrocytes with $P$. falciparum were stained with $5 \mu \mathrm{M}$ CellRox for $30 \mathrm{~min}$ in PBS. In the last $5 \mathrm{~min}$ of incubation, SYTO 16 Green Fluorescent Nucleic Acid Stain (Molecular Probes ${ }^{\oplus}$ ) was added to a final concentration of $40 \mathrm{nM}$. The same procedure was run in parallel with uninfected and infected erythrocytes incubated with $0.5 \mu \mathrm{M} \mathrm{H}_{2} \mathrm{O}_{2}$ (positive control) or $0.5 \mu \mathrm{M} \mathrm{H} \mathrm{H}_{2} \mathrm{O}_{2}$ plus $75 \mu \mathrm{M} \alpha$-tocopherol (negative control) $30 \mathrm{~min}$ before the CellRox addition. The cells were washed $3 \times$ with PBS and analyzed by flow cytometry in a Guava Easycyte Mini System (Millipore, Billerica, USA) for the fluorescence measured with excitation wave length $488 \mathrm{~nm}$ and emission filters of 680/40 $\mathrm{nm}$ (red) and $525 / 30 \mathrm{~nm}$ (green). The levels of ROS were measured in untreated and treated cultures with the half-maximal inhibitory concentration $\left(\mathrm{IC}_{50}\right)$ of usnic acid $(25 \mu \mathrm{M})$ for $48 \mathrm{~h}$ before the analysis [11].

\section{Oxidation of a-tocopherol standard}

The oxidation of $\alpha$-tocopherol was performed as described by Liebler et al. [32]. $\alpha$-tocopherolquinone was obtained from the oxidation of $4 \mathrm{mg} \alpha$-tocopherol by addition $0.15 \mathrm{mM}$ Cumene hydroperoxide (CumOOH) and $0.1 \mathrm{mM}$ ferrous ammonium sulphate $\left(\mathrm{Fe}\left(\mathrm{NH}_{4}\right)_{2}\left(\mathrm{SO}_{4}\right)_{2}\right)$ in a final volume $200 \mu \mathrm{l} 50 \mathrm{mM}$ Tris, $\mathrm{pH}$ 7. After $30 \mathrm{~min}$ incubation at $37^{\circ} \mathrm{C}$, the oxidation was stopped by adding up to $1 \mathrm{mM}$ deferoxamine mesylate, and the mixture was extracted three times with $1 \mathrm{ml}$ hexane. The hexane extract was evaporated and submitted to RP-HPLC and GCMS analysis.

\section{Reversed phase-high-performance liquid chromatography (RP-HPLC)}

The stationary phase was a Phenomenex Luna C18 column $(250 \mathrm{~mm} \times 4.6 \mathrm{~mm} \times 5 \mu \mathrm{m})$ (Phenomenex, Torrance, USA) coupled to a pre-C18 column (Phenomenex, Torrance, USA), a diode array detector (DAD) type Gilson 170 (270 and $295 \mathrm{~nm}$ ) and a fraction collector FC203B. The software used for data processing was the Trilution ${ }^{\mathrm{TM}}$ LC 3.0 System Software. An isocratic system with $1 \mathrm{ml} / \mathrm{min}$ methanol was used, and the fractions were collected per minute [32]. The resulting fractions were dried, resuspended in $600 \mu \mathrm{l}$ of liquid of scintillation mixture (Perkin-Elmer Life Sciences, Waltham, USA) and 
the radioactivity were monitored with a Beckman 5000 ß-radiation scintillation counter (Beckman, Los Angeles, USA).

\section{Gas chromatography - mass spectrometry (GC-MS)}

A Y2K ion trap mass spectrometer (MS) PolarisQ System (Finnigan ThermoQuest Inc., San Jose, USA) equipped with a nano-source type electron impact ionization (EI) was used. A TRACE GC equipped with a $30 \mathrm{~m} \times 25 \mathrm{~mm} \times$ $0.25 \mu \mathrm{m}$ DB- $5 \mathrm{~ms}$ column and $1 \mathrm{ml} / \mathrm{min}$ helium as mobile phase was used.

The analysis conditions were an initial oven temperature of $120^{\circ} \mathrm{C}$ for 4 min then a ramp of $20^{\circ} \mathrm{C} / \mathrm{min}$ until $300{ }^{\circ} \mathrm{C}$. This temperature was maintained for additional $3 \mathrm{~min}$. The injector and transferline temperatures were $215{ }^{\circ} \mathrm{C}$ and $275{ }^{\circ} \mathrm{C}$, respectively. The ion source was maintained at $200{ }^{\circ} \mathrm{C}$, and 2 segments were acquired by first monitoring a range of $m / z 50$ to 500 (fullscan) and then a second monitoring of the fragmentation (MS/MS) of the ion at $m / z$ 446. The excitation energy scale for fragmentation was 0.225 and $0.85 \mathrm{~V}$. The monitored fragment ions of tocopherolquinone were at $\mathrm{m} / z 150,203,221$ and 428 [32]. The mass spectra were analyzed using the Xcalibur data analysis program, version 1.3.

\section{Inhibition growth assay in vitro of $P$. falciparum}

The method described by Desjardins et al. [33] was employed to determine the $\mathrm{IC}_{50}$ in $48 \mathrm{~h}$ of cercosporin (Sigma-Aldrich, St. Louis, MO) in P. falciparum cultures. Cercosporin was diluted in dimethyl sulfoxide (DMSO) and then serially diluted in culture medium to reach the desired concentrations. Two controls were used, one with no treatment and another with the solvent in which the drug had been diluted. These tests were performed in cell culture 96-well plates (Eppendorf, Hamburg, Germany). Daily thin blood smears were made to control parasitaemia.

\section{Metabolic labelling}

Synchronous cultures of $P$. falciparum in trophozoite stage were metabolically labeled with $0.75 \mu \mathrm{Ci} / \mathrm{ml}$ of $\left[1(n)-{ }^{3} \mathrm{H}\right]$-geranylgeranyl pyrophosphate $\left(\left[{ }^{3} \mathrm{H}\right]\right.$ GGPP) $(14 \mathrm{Ci} / \mathrm{mmol}$, Amersham, Picataway, USA). After 12$16 \mathrm{~h}$, schizont stages were concentrated by the magnetic fractionation process [34]. The volume of the infected erythrocytes was measured, lyophilized and stored in liquid nitrogen for later analysis. In parallel, cultures were treated for $48 \mathrm{~h}$ with the $\mathrm{IC}_{50}$ of cercosporin or chloroquine. In this case, the metabolic labeling occurred between the last $12-16 \mathrm{~h}$ of treatment and the schizonts were concentrated as described above. It is important to emphasize the parasite culture was immediately lyophilized after magnetic column concentration and stored in liquid nitrogen to avoid unspecific oxidation of $\alpha$-tocopherol.

Extraction of vitamin $\mathrm{E}$ and its oxidation products from $P$. falciparum

$1.5 \times 10^{9}$ lyophilized erythrocytes infected with $P$. falcip$\operatorname{arum}(300 \mu \mathrm{l})$ metabolically labeled as described above were resuspended in $1 \mathrm{ml}$ deionized water in glass tubes. Cell lysis was achieved by ultrasonication in a Branson sonifier with three pulses of $5 \mathrm{~s}$ with $10 \%$ of potency and $10 \mathrm{~s}$ intervals between them at $4{ }^{\circ} \mathrm{C}$. The proteins were precipitated by adding $200 \mu \mathrm{l}$ ethanol-0.01\% butylated hydroxytoluene (BHT). After mixing for $1 \mathrm{~min}$, extraction was done three times with $2 \mathrm{ml}$ of hexane $-0.01 \%$ BHT. The sample was mixed for $1 \mathrm{~min}$ and centrifuged at $2700 \times g$ for $10 \mathrm{~min}$ at $4{ }^{\circ} \mathrm{C}$ [35]. The hexane extract of erythrocytes infected with $P$. falciparum was evaporated and submitted to RP-HPLC analysis. All the procedure was done avoiding light and heat.

\section{Statistical analysis}

Statistical significance was determined by Student's ttest, one-way ANOVA or nonlinear regression (dose response) analysis using Prism 5.3 software (GraphPad, La Jolla, USA) or Origin 8 (OriginLab Corporation, Northampton, USA).

\section{Results}

\section{CellRox effectively detected oxidative stress}

To determine whether CellRox could effectively visualize oxidative stress levels in P. falciparum, fluorescence microscopy was performed. For this, the response of the culture exposed to an oxidative stress source was tested (Additional file 1: Figure S1).

The culture that was not treated with $\mathrm{H}_{2} \mathrm{O}_{2}$ showed a basal level of oxidative stress in infected and noninfected erythrocytes, while the treated ones showed a strong increase in mean fluorescence exclusively in the three stages of the parasite.

\section{CellRox stained erythrocytes can also be measured by cytometry}

The two populations observed in parasite cultures stained with SYTO 16 Green were classified as infected and noninfected erythrocytes (Fig. 1a, b). In parasite cultures stained with CellRox, it was observed that erythrocytes with increased granularity (corresponding to infected erythrocytes) showed a highest basal level of oxidation compared with non-infected erythrocytes (Fig. 1c, d). The incubation of infected and non-infected erythrocytes with both probes (Fig. 1e, f) indicated that only in infected erythrocytes is it possible to observe a population with a diagonal displacement (Fig. 1e, black circle). The basal level of oxidative stress in schizonts (Fig. 1e, black arrow) 

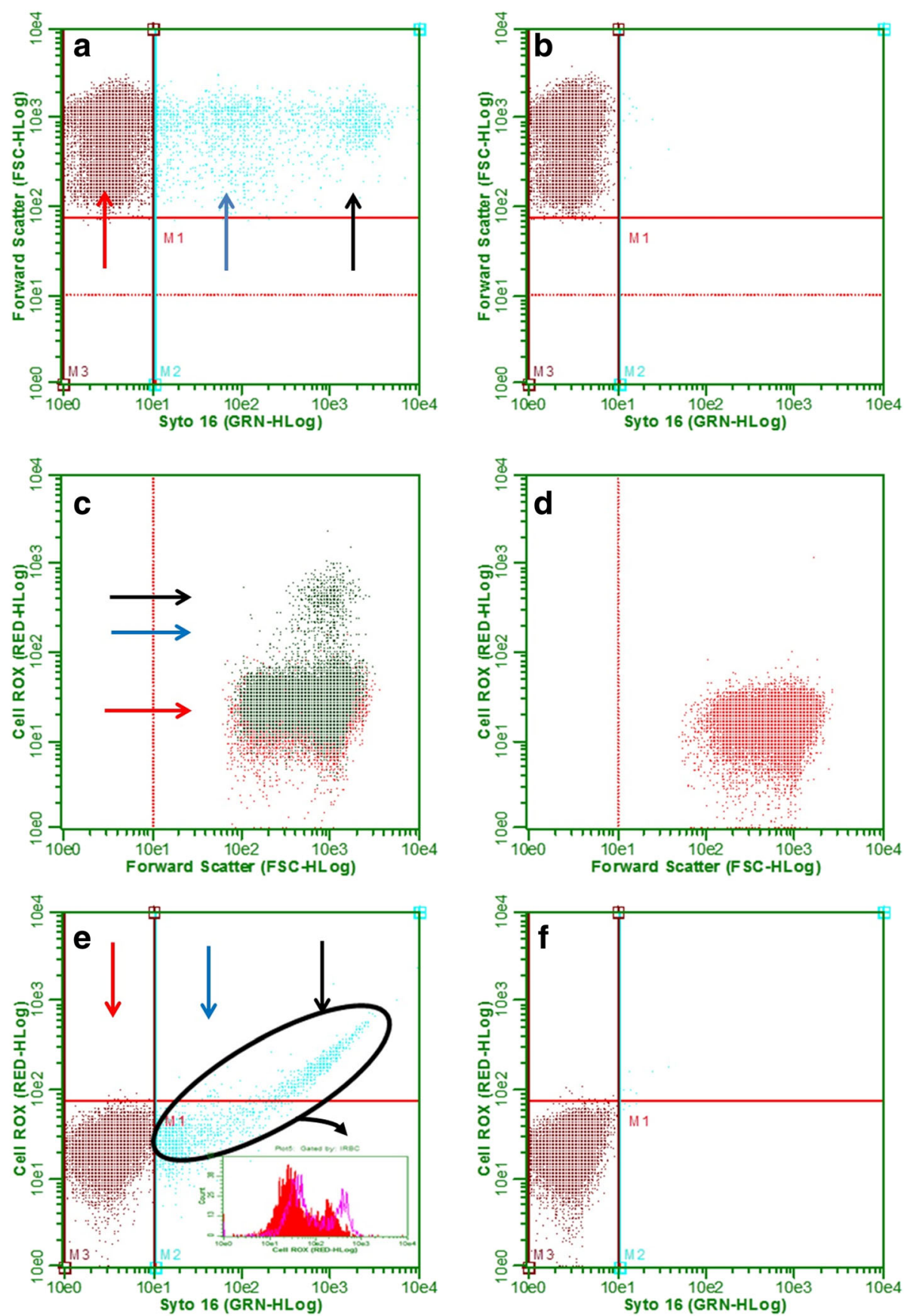

Fig. 1 Parameters used in the analysis of ROS levels. a Infected erythrocytes stained with SYTO 16 green. b Uninfected erythrocytes stained with SYTO 16 green. c Infected erythrocytes stained with CellRox. d Uninfected erythrocytes stained with CellRox. e Infected erythrocytes cells stained with SYTO 16 green and CellRox-histogram comparing the ROS levels in infected erythrocytes challenge (pink line) and unchallenged (red solid) with $\mathrm{H}_{2} \mathrm{O}_{2}$ in 20 min of incubation with CellRox. $\mathbf{f}$ Uninfected erythrocytes stained with SYTO 16 green and CellRox. Red arrow: uninfected erythrocytes; blue arrow: trophozoites; black arrow: schizonts; black circle: infected erythrocytes population

were higher than in trophozoites (Fig. 1e, blue arrow), a fact already described by Butzloff et al. [15]. With these parameters standardized, we analyzed only the infected erythrocytes population in cultures previously challenged with $\mathrm{H}_{2} \mathrm{O}_{2}$.
To determine the time to detecting the difference between the redox state of challenged and unchallenged cultures, the ROS generation was monitored at different times of incubation (Additional file 1: Figure S2). It is possible to observe that the ROS levels in the culture 
challenge with $\mathrm{H}_{2} \mathrm{O}_{2}$ were higher compared with control in all time course (t-test: $\left.t_{(4)}=16.40, P<0.0001\right)$. The $20 \mathrm{~min}$ of incubation was chosen because at 0 and 10 the ROS levels were increasing and at 30 and $40 \mathrm{~min}$ a plateau of ROS levels was reached and presented a higher variation. The histogram in the bottom of Fig. 1e demonstrates that the infected erythrocytes pre-incubated with $\mathrm{H}_{2} \mathrm{O}_{2}$ (pink line) showed a higher level of oxidative stress than the unchallenged infected erythrocytes (red solid) after 20 min of incubation with CellRox.

Usnic acid treatment increases ROS levels in P. falciparum Using the benchmark parameters described above, we analyzed parasite cultures treated in vitro with usnic acid, the inhibitor of $\alpha$-tocopherol biosynthesis in $P$. falciparum [11] (Fig. 2).

The oxidative stress levels showed no significant difference in the treatments that were not challenged with $\mathrm{H}_{2} \mathrm{O}_{2}$. When parasites were challenged with the prooxidant $\mathrm{H}_{2} \mathrm{O}_{2}$, we detected an increase of $63 \%$ in oxidative stress levels in the culture treated with usnic acid $\left(\mathrm{H}_{2} \mathrm{O}_{2}\right.$ UA) when compared with the treated and not challenged culture (Basal UA) (ANOVA: $F_{(6,77)}=30.6$, $P<0.0001)$. The oxidative stress was maintained in basal levels when $75 \mu \mathrm{M}$ of vitamin $\mathrm{E}$ was added to cultures treated with usnic acid and challenged with $\mathrm{H}_{2} \mathrm{O}_{2}\left(\mathrm{H}_{2} \mathrm{O}_{2}\right.$ UAT) compared to cultures where no $\alpha$-tocopherol was added $\left(\mathrm{H}_{2} \mathrm{O}_{2}\right.$ UA) (ANOVA: $\left.F_{(6,77)}=30.6, P<0.0001\right)$. (Fig. 2).

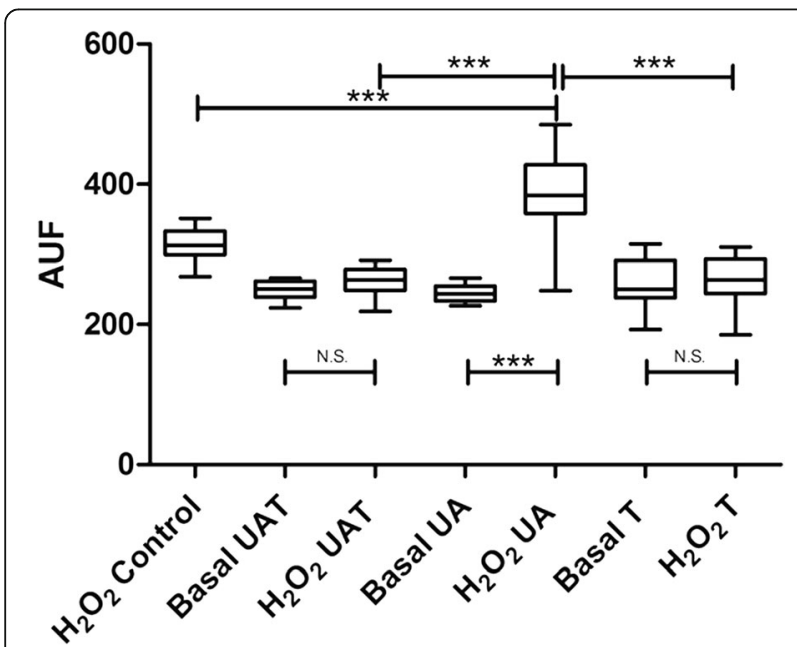

Fig. 2 Levels of ROS in erythrocytes infected with $P$. falciparum. Cytometry analysis of infected erythrocytes challenged or not (basal) with the pro-oxidant $\mathrm{H}_{2} \mathrm{O}_{2}$. The levels of oxidative stress were evaluated in different treatments: $\mathrm{H}_{2} \mathrm{O}_{2}$, hydrogen peroxide; UAT, usnic acid plus $75 \mu \mathrm{M}$ a-tocopherol; UA, usnic acid and T, 75 uM a-tocopherol. Abbreviations: AUF: arbitrary unit of fluorescence; N.S.: not significant (ANOVA: $F_{(6,77)}=30.6, P<0.0001$ )
Changes in the ratio of a-tocopherolquinone and atocopherol occur as a result of a redox imbalance Until now, vitamin E biosynthesized by $P$. falciparum was only indirectly implied as an antioxidant [11]. If vitamin $\mathrm{E}$ actively participates in the redox system of the parasite, oxidized forms of vitamin $E$, such as $\alpha$ tocopherolquinone, should be detectable.

To determine the retention time of $\alpha$-tocopherolquinone in the RP-HPLC analysis of metabolically labelled parasites, the $\alpha$-tocopherol standard was oxidized, and its quinone was purified by RP-HPLC (Additional file 1: Figure S3). The fractions resulting from chromatography purification were analyzed by GC-MS to confirm the oxidation of $\alpha$-tocopherol standard to $\alpha$-tocopherolquinone. Fraction 29 was identified as $\alpha$-tocopherol, and fraction 21 had an identical MS/MS spectrum compared to the $\alpha$-tocopherolquinone present in the GC-MS library (Additional file 1: Figure S4).

The ion at $m / z 446$ corresponds to the molecular mass of $\alpha$-tocopherolquinone in the GC-MS library (Additional file 1: Figure $S 4 b)$ is present in the analyzed HPLC fraction 21 (Additional file 1: Figure S4a) and also an ion at $m / z 428$, corresponding to the molecular mass without water. The ion fragmentation profile of ion at $m / z 446$ was identical to the pattern, thereby confirming the identity of the compound eluted in the fraction 21.

To establish if exogenous sources of oxidative stress (e.g. cercosporin and chloroquine) lead to an imbalance of $\alpha$-tocopherolquinone and tocopherol ratio, we used chloroquine ( $\left.\mathrm{IC}_{50} 7 \mathrm{nM}\right)$ and cercosporin $\left(\mathrm{IC}_{50} 177 \mathrm{nM}\right)$. The $\mathrm{IC}_{50}$ for cercosporin was calculated for the 3D7 strain (Additional file 1: Figure S5). Once confirmed the elution time of $\alpha$-tocopherolquinone and determined the $\mathrm{IC}_{50}$ of cercosporin, treated and untreated radiolabeled parasite extracts were analyzed by RP-HPLC. The ratio between the radioactivity in the fractions corresponding to the $\alpha$-tocopherolquinone and $\alpha$-tocopherol was calculated in infected erythrocytes treated with cercosporin or chloroquine and compared with untreated control cultures (Fig. 3).

The ratio between $\alpha$-tocopherolquinone and $\alpha$ tocopherol increased significantly from $0.31 \pm 0.16$ in control to $0.97 \pm 0.19$ and $1.04 \pm 0.21$ in chloroquine and cercosporin treatments, respectively (ANOVA: $F_{(2,6)}=$ 12.92, $P=0.006)$. This indicates that an exogenous source of oxidative stress interferes in the pool of $\alpha$ tocopherol and its oxidized form, probably as a means of maintaining the redox balance.

\section{Discussion}

The genus Plasmodium comprises a group of unicellular parasites that have to deal with intense oxidative stress caused by several factors, such as metabolism of haemoglobin,and blast of oxidative radicals characteristic to 


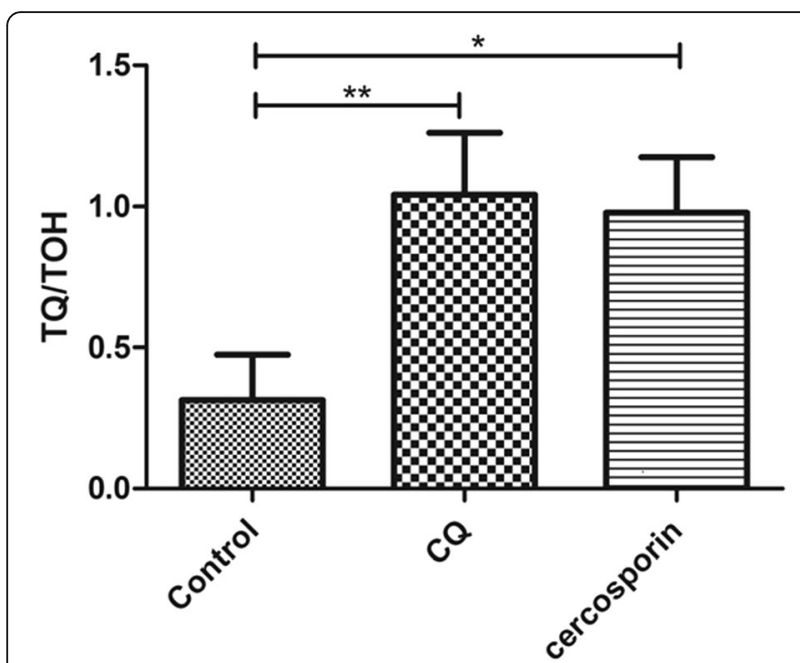

Fig. 3 Changes in the ratio of a-tocopherol and a-tocopherolquinone in infected erythrocytes. Ratio between TQ (a-tocopherolquinone) and $\mathrm{TOH}$ (a-tocopherol) in control, CQ (chloroquine) and cercosporin (ANOVA: $F_{(2,6)}=12.92, P=0.006$ )

neutrophils in inflammatory process [36]. Erythrocytic stages of Plasmodium are exposed to a number of events that induce oxidative stress [37] and the parasite has developed a number of mechanisms to deal with radicals [38]. Similar to other species, Plasmodium disposes of vitamin $\mathrm{E}$ to regulate redox events. Our data show that vitamin E biosynthesized by $P$. falciparum via the isoprenoid pathway plays a role in the redox system of the infected erythrocyte. It was shown that the treatment with usnic acid inhibits vitamin E biosynthesis in $P$. falciparum [11] and in our hands this treatment increases the susceptibility to ROS formation when the culture was challenged with the oxidant, leading to oxidative stress (Fig. 2). Similar to this result, in spinach thylakoids, $\alpha$-tocopherol in combination with vitamin $\mathrm{K} 1$ and plastoquinone act as scavengers of superoxide formed by photosystem I in plant photosynthesis [39]. The formation of hydrogen peroxide is inhibited which results in the protection of thylakoid membranes against lipid peroxidation [39].

The presence of the oxidized form of $\alpha$-tocopherol, $\alpha$ tocopherolquinone, in P. falciparum was characterized by metabolic labelling and RP-HPLC analysis. Chloroquine exerts its effects by hampering hemozoin formation [14], and cercosporin is present in the fungal plant pathogen Cercospora nicotinae, and is a natural singlet oxygen generator $\left({ }^{1} \mathrm{O}_{2}\right)[40,41]$. Cercosporin has been previously used to measure ${ }^{1} \mathrm{O}_{2}$ formation in $P$. falciparum [15]. However, the authors of the study did not describe the $\mathrm{IC}_{50}$ of cercosporin for the parasite. Here, we calculated the $\mathrm{IC}_{50}$ of cercosporin for P. falciparum 3D7 strain.

The ratio between $\alpha$-tocopherolquinone and $\alpha$ tocopherol increased in chloroquine or cercosporin treatments (Fig. 3). The same effect was described in plants under water stress [42], high light stress [43] and nutrient deprivation [44]. In animals, this phenomenon is also observed in different types of oxidative stress such as hyperoxia [45], patients who had undergone an aortic cross-clamping operation [46], fatigue induced by overnight desk work [47] and cognitive impairment in elderly people [48].

The redox imbalance and change in $\alpha$-tocopherol and $\alpha$-tocopherolquinone ratio reinforces the view that vitamin $\mathrm{E}$ biosynthesized by the parasite participates in the redox system present in the infected erythrocyte. However, the treatment with the $\mathrm{IC}_{50}$ of usnic acid did not change the $\mathrm{IC}_{50}$ values of chloroquine (data not shown). The parasite may possess other mechanisms to deal with redox imbalance when the vitamin $\mathrm{E}$ biosynthesis is inhibited. For example, infected erythrocytes lose the ability to biosynthesizes glutathione de novo because the intermediate $\gamma$-glutamyl-cysteine is depleted from the host cell [49]. This disadvantage is compensated for by the exportation of glutathione oxidized by the parasite into the cytoplasm of erythrocyte, where it is reduced by the glutathione reductase from the cell and by the enzymes of pentose's cycle [49].

Given the importance of the antioxidant function represented by $\alpha$-tocopherol and $\alpha$-tocopherolquinone for the parasite, we investigated if this system could be useful to avoid the oxidative environment. Here, the system was capable of protecting the parasite from elevated oxidative stress (Fig. 2).

The use of $\alpha$-tocopherol and $\alpha$-tocopherolquinone as a membrane antioxidant can also be an alternative route to avoid intense oxidative stress caused by immune interactions on membranes of erythrocytes. The hostile environment can change parasite metabolism and permit adaptation in the cell cycle to the parasite adapted to achieve the new invertebrate host in a gametocyte formation [50,51]. The time to resist hostile environments until infection of the invertebrate host is essential for life-cycle perpetuation, and $\alpha$-tocopherol and $\alpha$ tocopherolquinone can be an additional antioxidant system in this process. These hypotheses must be studied.

We showed that $\alpha$-tocopherol biosynthesized by $P$ falciparum is found in its oxidized form as a defence mechanism against oxidative stress, but we cannot discard the idea that $\alpha$-tocopherol from the host can be used for the same purpose.

\section{Conclusions}

$\alpha$-tocopherol appears to play an important function as an antioxidant against environmental stress, including maintaining ROS levels. Furthermore, the metabolic pathway of vitamin $\mathrm{E}$ biosynthesis could be an interesting target for the development of drugs against P. falciparum. 


\section{Additional file}

Additional file 1: Figure S1. Imaging evaluation of CellRox. Figure S2. Time course of ROS generation. Figure S3. RP-HPLC purification of a-tocopherol and its oxidation product. Figure S4. GC/MS identification of tocopherolquinone. Figure S5. Determination in vitro of inhibitory concentration of $50 \%$ of the growth of cercosporin in $P$. falciparum. (DOCX $847 \mathrm{~kb})$

\section{Abbreviations}

O.- ${ }_{2}$ : Superoxide anion; $\left[{ }^{3} \mathrm{H}\right] \mathrm{GGPP}:\left[1(\mathrm{n})-{ }^{3} \mathrm{H}\right]$-geranylgeranyl pyrophosphate; BHT: Butylated hydroxytoluene; $\mathrm{CumOOH}$ : Cumene hydroperoxide; DAD: Diode array detector; DMSO: Dimethylsulfoxide; FP: Ferriprotoporphyrin IX; GC-MS: Gas chromatography-mass spectrometry; IC 50 : Half-maximal inhibitory concentration; IPP: Isopentenyl pyrophosphate; MEP: 2-C-methyl-Derythritol 4-phosphate; OH: Hydroxyl radical; PBS: Phosphate-buffered saline; RNS: Reactive nitrogen species; ROS: Reactive oxygen species; RPHPLC: Reversed-phase high-performance liquid chromatography

\section{Acknowledgements}

The authors would like to thank S. Wendel (Sírio Libanês Hospital, NESTA) for the gift of erythrocytes and to G. Wunderlich for reading the manuscript.

\section{Funding}

R.A.C.S. and W.L.F. are fellows from the Fundação de Amparo à Pesquisa do Estado de São Paulo (FAPESP). This research was supported by grants from FAPESP and CNPq

\section{Availability of data and materials}

All data generated or analysed during this study are included in this published article and its additional files.

\section{Authors' contributions}

RACS and WLF designed and performed the experiments, analyzed the data and wrote the manuscript; EAK and AMK conceived and supervised the study, analyze the data and wrote the manuscript. All authors read and approved the final manuscript.

\section{Ethics approval and consent to participate}

Approval for the study was provided by the Ethical Committee of the Institute of Biomedical Sciences, University of São Paulo, São Paulo, Brazil.

\section{Consent for publication}

Not applicable.

\section{Competing interests}

The authors declare that they have no competing interests.

\section{Publisher's Note}

Springer Nature remains neutral with regard to jurisdictional claims in published maps and institutional affiliations.

\section{Received: 18 January 2017 Accepted: 25 September 2017}

\section{Published online: 10 October 2017}

\section{References}

1. World Health Organization (WHO). Geneva: World Malaria Report; 2015.

2. Ariey F, Witkowski B, Amaratunga C, Beghain J, Langlois AC, Khim N, et al. A molecular marker of artemisinin-resistant Plasmodium falciparum malaria. Nature. 2014:505:50-5.

3. Cassera MB, Gozzo FC, D'Alexandri FL, Merino EF, del Portillo HA, Peres VJ, et al. The methylerythritol phosphate pathway is functionally active in all intraerythrocytic stages of Plasmodium falciparum. J Biol Chem. 2004:279:51749-59.

4. Jomaa H, Wiesner J, Sanderbrand S, Altincicek B, Weidemeyer C, Hintz M, et al. Inhibitors of the nonmevalonate pathway of isoprenoid biosynthesis as antimalarial drugs. Science. 1999;285:1573-6.
5. Yeh E, DeRisi JL. Chemical rescue of malaria parasites lacking an apicoplast defines organelle function in blood-stage Plasmodium falciparum. PLoS Biol. 2011;9:e1001138.

6. Couto AS, Kimura EA, Peres VJ, Uhrig ML, Katzin AM. Active isoprenoid pathway in the intra-erythrocytic stages of Plasmodium falciparum: presence of dolichols of 11 and 12 isoprene units. Biochem J. 1999:341(Pt 3):629-37.

7. De Macedo CS, Uhrig ML, Kimura EA, Katzin AM. Characterization of the isoprenoid chain of coenzyme Q in Plasmodium falciparum. FEMS Microbiol Lett. 2002;207:13-20.

8. D'Alexandri FL, Kimura EA, Peres VJ, Katzin AM. Protein dolichylation in Plasmodium falciparum. FEBS Lett. 2006;580:6343-8.

9. Moura IC, Wunderlich G, Uhrig ML, Couto AS, Kimura EA, Peres VJ, et al. Limonene arrests parasite development and inhibits isoprenylation of proteins in Plasmodium falciparum. Antimicrob Agents Chemother. 2001;45:2553-8.

10. Tonhosolo R, D'Alexandri FL, de Rosso W, Gazarini ML, Matsumura MY, Peres VJ, et al. Carotenoid biosynthesis in intraerythrocytic stages of Plasmodium falciparum. J Biol Chem. 2009:284:9974-85.

11. Sussmann RAC, Angeli CB, Peres VJ, Kimura EA, Katzin AM. Intraerythrocytic stages of Plasmodium falciparum biosynthesize vitamin E. FEBS Lett. 2011;585:3985-91.

12. Tonhosolo R, Gabriel HB, Matsumura MY, Cabral FJ, Yamamoto MM, D'Alexandri $\mathrm{FL}$, et al. Intraerythrocytic stages of Plasmodium falciparum biosynthesize menaquinone. FEBS Lett. 2010;584:4761-8.

13. Cumming JN, Ploypradith P, Posner GH. Antimalarial activity of artemisinin (Qinghaosu) and related trioxanes: mechanism (s) of action. Adv Pharmacol. 1997;37:253-97.

14. Chugh M, Sundararaman V, Kumar S, Reddy VS, Siddiqui WA, Stuart KD, et al. Protein complex directs hemoglobin-to-hemozoin formation in Plasmodium falciparum. Proc Natl Acad Sci U S A. 2013;110:5392-7.

15. Butzloff S, Groves MR, Wrenger C, Muller IB. Cytometric quantification of singlet oxygen in the human malaria parasite Plasmodium falciparum. Cytometry A. 2012:81:698-703.

16. Dockrell HM, Playfair JH. Killing of Plasmodium yoelii by enzyme-induced products of the oxidative burst. Infect Immun. 1984;43:451-6.

17. Meierjohann S, Walter RD, Muller S. Glutathione synthetase from Plasmodium falciparum. Biochem J. 2002;363:833-8.

18. Farber PM, Becker K, Muller S, Schirmer RH, Franklin RM. Molecular cloning and characterization of a putative glutathione reductase gene, the PfGR2 gene, from Plasmodium falciparum. Eur J Biochem. 1996;239:655-61.

19. Becuwe P, Slomianny C, Camus D, Dive D. Presence of an endogenous superoxide dismutase activity in three rodent malaria species. Parasitol Res. 1993;79:349-52

20. Krauth-Siegel RL, Muller JG, Lottspeich F, Schirmer RH. Glutathione reductase and glutamate dehydrogenase of Plasmodium falciparum, the causative agent of tropical malaria. Eur J Biochem. 1996:235:345-50.

21. O'Brien E, Kurdi-Haidar B, Wanachiwanawin W, Carvajal JL, Vulliamy TJ, Cappadoro M, et al. Cloning of the glucose 6-phosphate dehydrogenase gene from Plasmodium falciparum. Mol Biochem Parasitol. 1994;64:313-26.

22. Kanzok SM, Schirmer RH, Turbachova I, lozef R, Becker K. The thioredoxin system of the malaria parasite Plasmodium falciparum. Glutathione reduction revisited. J Biol Chem. 2000:275:40180-6.

23. Krnajski Z, Gilberger TW, Walter RD, Muller S. The malaria parasite Plasmodium falciparum possesses a functional thioredoxin system. Mol Biochem Parasitol. 2001;112:219-28

24. Krnajski Z, Walter RD, Muller S. Isolation and functional analysis of two thioredoxin peroxidases (peroxiredoxins) from Plasmodium falciparum. Mol Biochem Parasitol. 2001;113:303-8.

25. Kawazu S, Ikenoue N, Takemae H, Komaki-Yasuda K, Kano S. Roles of 1-Cys peroxiredoxin in haem detoxification in the human malaria parasite Plasmodium falciparum. FEBS J. 2005:272:1784-91.

26. Sattler SE, Gilliland LU, Magallanes-Lundback M, Pollard M, DellaPenna D. Vitamin $\mathrm{E}$ is essential for seed longevity and for preventing lipid peroxidation during germination. Plant Cell. 2004;16:1419-32.

27. Maeda H, Sakuragi Y, Bryant DA, Dellapenna D. Tocopherols protect Synechocystis sp. strain PCC 6803 from lipid peroxidation. Plant Physiol. 2005;138:1422-35.

28. Schneider C. Chemistry and biology of vitamin E. Mol Nutr Food Res. 2005:49:7-30

29. Wolf $\mathrm{G}$. The discovery of the antioxidant function of vitamin $\mathrm{E}$ : the contribution of Henry A. Mattill. J Nutr. 2005;135:363-6.

30. Trager W, Jensen J. Human malaria parasites in continuous culture. Science. 1976;193:673-5. 
31. Goodyer ID, Johnson J, Eisenthal R, Hayes DJ. Purification of mature-stage Plasmodium falciparum by gelatine flotation. Ann Trop Med Parasitol. 1994;88:209-11.

32. Liebler DC, Burr JA, Ham AJ. Gas chromatography-mass spectrometry analysis of vitamin $\mathrm{E}$ and its oxidation products. Methods Enzymol. 1999;299:309-18.

33. Desjardins RE, Canfield CJ, Haynes JD, Chulay JD. Quantitative assessment of antimalarial activity in vitro by a semiautomated microdilution technique. Antimicrob Agents Chemother. 1979;16:710-8.

34. Karl S, Davis TM, St Pierre TG. Parameterization of high magnetic field gradient fractionation columns for applications with Plasmodium falciparum infected human erythrocytes. Malar J. 2010;9:116.

35. Gueguen S, Herbeth B, Siest G, Leroy P. An isocratic liquid chromatographic method with diode-array detection for the simultaneous determination of alpha-tocopherol, retinol, and five carotenoids in human serum. J Chromatogr Sci. 2002:40:69-76.

36. Shacter E, Beecham EJ, Covey JM, Kohn KW, Potter M. Activated neutrophils induce prolonged DNA damage in neighboring cells. Carcinogenesis. 1988:9:2297-304

37. DuranBedolla J, Rodriguez M, SaldanaNavor V, RivasArancibia S, Cerbon M, Rodriguez M. Oxidative stress: production in several processes and organelles during Plasmodium sp. development. Oxid Antioxid Med Sci. 2013;2:93-100.

38. Müller S. Redox and antioxidant systems of the malaria parasite Plasmodium falciparum. Mol Microbiol. 2004;53:1291-305.

39. Kruk J, Jemiola-Rzeminska M, Burda K, Schmid GH, Strzalka K. Scavenging of superoxide generated in photosystem I by plastoquinol and other prenyllipids in thylakoid membranes. Biochemistry. 2003:42:8501-5.

40. Daub ME, Hangarter RP. Light-induced production of singlet oxygen and superoxide by the fungal toxin, cercosporin. Plant Physiol. 1983;73:855-7.

41. Daub ME, Li M, Bilski P, Chignell CF. Dihydrocercosporin singlet oxygen production and subcellular localization: a possible defense against cercosporin phototoxicity in Cercospora. Photochem Photobiol. 2000;71:135-40.

42. Munné-Bosch S, Shikanai T, Asada K. Enhanced ferredoxin-dependent cyclic electron flow around photosystem I and alpha-tocopherol quinone accumulation in water-stressed ndhB-inactivated tobacco mutants. Planta. 2005:222:502-11.

43. Kobayashi N, DellaPenna D. Tocopherol metabolism, oxidation and recycling under high light stress in Arabidopsis. Plant J. 2008;55:607-18.

44. Baszynski T, Barr R, Crane FL. Relationship between alpha-tocopherol and alpha-tocopherylquinone in mineral-deficient maize plants. Plant Physiol. 1972;49:666-7.

45. Kanazawa H, Miyata C, Nagata Y, Urano S, Matsushima Y. Determination of alpha-tocopherol and alpha-tocopherylquinone in rat tissues and plasma by high-performance liquid chromatography with electrochemical detection. Chem Pharm Bull (Tokyo). 2000;48:1462-6.

46. Murphy ME, Kolvenbach R, Aleksis M, Hansen R, Sies H. Antioxidant depletion in aortic crossclamping ischemia: increase of the plasma alpha-tocopheryl quinone/alpha-tocopherol ratio. Free Radic Biol Med. 1992;13:95-100.

47. Shichiri M, Harada N, Ishida N, Komaba LK, Iwaki S, Hagihara Y, et al. Oxidative stress is involved in fatigue induced by overnight deskwork as assessed by increase in plasma tocopherylhydroqinone and hydroxycholesterol. Biol Psychol. 2013;94:527-33.

48. Ravaglia G, Forti P, Lucicesare A, Pisacane N, Rietti E, Mangialasche F, et al. Plasma tocopherols and risk of cognitive impairment in an elderly Italian cohort. Am J Clin Nutr. 2008;87:1306-13.

49. Atamna $\mathrm{H}$, Ginsburg $\mathrm{H}$. The malaria parasite supplies glutathione to its host cell - investigation of glutathione transport and metabolism in human erythrocytes infected with Plasmodium falciparum. Eur J Biochem. 1997;250: 670-9.

50. Carter LM, Kafsack BFC, Llinas M, Mideo N, Pollitt LC, Reece SE. Stress and sex in malaria parasites: Why does commitment vary? Evol Med Public Health. 2013:2013:135-47.

51. Peatey CL, Skinner-Adams TS, Dixon MWA, McCarthy JS, Gardiner DL, Trenholme KR. Effect of antimalarial drugs on Plasmodium falciparum gametocytes. I Infect Dis. 2009;200:1518-21.

\section{Submit your next manuscript to BioMed Central and we will help you at every step:}

- We accept pre-submission inquiries

- Our selector tool helps you to find the most relevant journal

- We provide round the clock customer support

- Convenient online submission

- Thorough peer review

- Inclusion in PubMed and all major indexing services

- Maximum visibility for your research

Submit your manuscript at www.biomedcentral.com/submit

Biomed Central 